\title{
Effect of perforations on the bearing capacity of shallow foundation on clay
}

\begin{tabular}{|c|c|}
\hline Journal: & Canadian Geotechnical Journal \\
\hline Manuscript ID & cgj-2017-0647.R2 \\
\hline Manuscript Type: & Note \\
\hline $\begin{array}{r}\text { Date Submitted by the } \\
\text { Author: }\end{array}$ & 22-Jul-2018 \\
\hline Complete List of Authors: & $\begin{array}{l}\text { Liu, Run; Tianjin University, } \\
\text { Liu, Meng-Meng; Tianjin University } \\
\text { Tian, Yinghui; Centre for Offshore Foundation Systems and ARC } \\
\text { CoE for Geotechnical Science and Engineering, The University of } \\
\text { Western Australia } \\
\text { Wu, Xinli; Pennsylvania State University }\end{array}$ \\
\hline $\begin{array}{r}\text { Is the invited manuscript } \\
\text { for consideration in a } \\
\text { Special Issue? : }\end{array}$ & Not applicable (regular submission) \\
\hline Keyword: & $\begin{array}{l}\text { shallow foundation, clay, finite element analysis, perforation, } \\
\text { bearing capacity }\end{array}$ \\
\hline
\end{tabular}




\title{
Effect of perforations on the bearing capacity of shallow foundation on clay
}

\author{
Run Liu ${ }^{1}$, Meng-meng Liu ${ }^{1}$, Ying-hui Tian ${ }^{1}$, Xinli $\mathrm{Wu}^{2}$ \\ ${ }^{1}$ State Key Laboratory of Hydraulic Engineering Simulation and Safety, Tianjin University, Tianjin, \\ China. ${ }^{2}$ College of Engineering, Pennsylvania State University, Pennsylvania, USA.
}

Abstract

As a kind of shallow foundation, mudmat serves as the seabed support structure for subsea wells, pipeline manifolds and pipeline terminations. The shallow foundations are usually designed with perforations to facilitate installation and removal, but the influence of these perforations has not been fully understood. This paper presents a method to analyze the bearing capacities of both $2 \mathrm{D}$ and $3 \mathrm{D}$ perforated shallow foundations using finite element analysis. The soil was idealized as a Tresca material, with the undrained strength increasing linearly with depth. The outcome indicates that perforation has non-negligible effects on the bearing capacity of shallow foundation. The bearing capacity decreases with increasing perforation ratio $R$, and the degree of reduction increases with the increase of the dimensionless ratio $k B / S_{u o}$. For $2 \mathrm{D}$ shallow foundation, there exist a critical perforation ratio $R$, when the perforation ratio is lower than the critical perforation ratio, the perforated foundation do not loss the bearing capacity. For 3D shallow foundation, the bearing capacity decreases immediately with the increase of perforation ratio $R$.

Key words: shallow foundation; clay; finite element analysis; perforation; bearing capacity.

\section{Introduction}

Mudmat a kind of shallow foundation is usually designed with perforation to facilitate installation and removal. Many existing studies have concentrated on the bearing capacity of foundation without perforation, such as Skempton (1951), Shield and Drucker (1953), Kusakabe et al. (1986), Michalowski (2001), Michalowski and Dawson (2002), Salgado et al. 
(2004), Gourvenec et al. (2006), Gourvenec (2007, 2008), Gourvenec and Steinepreis (2007), Yun et al. (2009), Taiebat and Carter (2000, 2002, 2010), Li et al. (2013), Feng et al. (2014), Shen et al. (2016), and Liu et al. (2016). Kong et al. (2017) introduced sequential limit analysis (SLA) as a method for modelling large plastic deformations of purely cohesive materials such as undrained clay. In recent years, increasing attention has been focused on the effect of perforation on the bearing capacity of shallow foundations. Martin et al. (2005) examined the bearing capacity of parallel strip footings on non-homogeneous clay and found that there were beneficial interactions between closely spaced footings. White et al (2005) compared the bearing capacities of solid and perforated shallow foundation installed on soft clay and found that the installation loads of the solid foundations matched the theoretical bearing capacities and that the perforation reduced the installation load in proportion to the perforated areas, ignoring arching and shape effects. Gourvenec (2007) examined the bearing capacities of rigidly connected two-strip footing systems at various separations in homogeneous soil. The results showed that the bearing capacities were mostly equal to those of the single footing of equivalent base area, with the exception of a small increase (approximately 5\%) in the vertical bearing capacities for footings separated by distances of less than one footing width. Bransby et al. (2011) and Tapper et al. (2014) investigated the performance of grillage foundations, which can be regarded as perforated foundations in sand with different spacings, grille thicknesses and number of grilles, and the results showed that the grillages were able to achieve the same capacities as solid foundations of the same breadth but required considerable penetration of the grillage. Tapper et al. (2015) investigated the bearing capacities of perforated shallow foundations and reported that perforation decreased the available foundation bearing areas, which reduced the capacities of the foundations during operation.

This paper presents a solution to evaluate the influence of the perforation of shallow 
foundation. Based on the study of $2 \mathrm{D}$ perforation foundation, the influence of perforation type, perforation number and perforation ratio on 3D foundation is also analyzed. Moreover, the influence mechanism of the perforation on the bearing capacity is discussed. In addition, several formulas are also proposed to quantify the influence of the perforation. It is hoped that this study will provide a useful starting point for the design of real perforation foundation.

\section{Finite Element Model}

\subsection{Geometry and mesh}

Finite element analyses were carried out using the commercially available ABAQUS software package to analyze the bearing capacities of perforated shallow foundation.

The FEA models include 2D shallow foundations (Figure 1) and 3D shallow foundations (Figure 2) to explore the bearing capacities of perforated shallow foundations. The 2D shallow foundation with $n$ perforations are assumed to be rigidly connected. The $3 \mathrm{D}$ shallow foundations are square shaped $(1 \times 1 \mathrm{~m})$ with square and circular perforations. For the calculated shallow foundations, $B$ refers to the width of the foundation, and $B^{*}$ refers to the effective width defined as the width of the footings between the perforations. $S$ refers to the perforation width, and $R$ refers to the perforation ratio $\left(R=A_{p} / A_{t}\right.$, where $A_{p}$ refers to the total perforation area, and $A_{t}$ refers to the total area). As it is hard to define $B^{*}$ and $S$ for foundations with circular perforations, the values of $B^{*}$ and $S$ must have values that are identical to those of a square perforation when they have the same perforation ratio and perforation number (Figure 2).

\section{Insert Figure 1 here.}

\section{Insert Figure 2 here.}

The foundations were modeled as ideal elastic-plastic steel material (Young's modulus 
$E=2.1 \times 10^{11} \mathrm{~Pa}$, Poisson's ratio $v=0.3$ ), and the soil was modeled as a Tresca material. Only undrained conditions were considered (with $v=0.49$ ), and soil shear strength was assumed to vary linearly with depth $z$ according to:

$$
S_{u}=S_{u o}+k z
$$

Where $S_{u o}$ is the shear strength at the mudline, $k$ is the shear strength gradient, and $z$ is the soil depth. A constant rigidity index of $G / S_{u}=333$ was adopted, which ensured failure at small deformations and thus minimized mesh distortion (Feng et al. 2014).

\section{Insert Figure 3 here.}

For $2 \mathrm{D}$ models, the soil width was $7 B$, and the soil height was $5 B$. For the $3 \mathrm{D}$ models, the soil width and length were $9 B$, and the soil height was $3.5 B$. These sizes ensured that the failure loads were unaffected by the boundary conditions. The mesh strategies of the FEA models were locally intensive, and various mesh densities were investigated to achieve time-efficient models without compromising accuracy. For 2D and 3D models, the minimum size was $0.02 B$, and the maximum size was $0.5 B$. The final model mesh sizes are shown in Figure 3. The whole models consisted of eight-node plane strains with reduced integration elements for the 2D model, and eight-node linear brick with hybrid elements for the 3D model, as these elements have high calculation efficiency and precision. The soil models were fully constrained at the base. The interface between the foundation and the soil was modeled as fully rough or smooth with separation allowed. With the rough contact all relative sliding motion between two contacting surfaces is prevented.

\subsection{Calculation accuracy}

\section{D FEA model}

For the unperforated footing located on non-homogeneous clay, the bearing capacity factor $N_{c}\left(N_{c}=Q_{u} / B S_{u}\right)$ varies with the dimensionless ratio $k B / S_{u o}$ and is calculated using 
the 2D FEA model. The FEA results are compared with the upper-bound calculation results (Kusakabe et al. 1986) and the method of characteristics results (Martin et al. 2005).

\section{Insert Figure 4 here.}

The ratio $k B / S_{u o}$ is related to soil strength (when the value of $k B / S_{u o}$ is larger, the soil strength is stronger when the footing size is fixed). As shown in Figure 4, when the shear strength gradient $k$ equals to zero (meaning the soil is homogeneous), the value of $N_{c}$ will be the classical theoretical solution 5.14. When the dimensionless ratio $k B / S_{u o}$ changes from 0 to 5 , the bearing capacity factor $N_{c}$ increases with the increase in the dimensionless ratio $\mathrm{kB} / \mathrm{S}_{\mathrm{uo}}$, meaning that the increase in shear strength gradient $k$ does improve the bearing capacity. In addition, the values and relationships between $N_{c}$ and $k B / S_{u o}$ are helpful for the later study.

For different methods, the FEA results are always less than the upper-bound calculations and greater than the method of characteristics, except for several initial values. This pattern indicates that the calculation accuracy of the 2D FEA model is satisfactory.

\section{D FEA model}

For the unperforated foundations located on homogeneous clay, the bearing capacity factors $N_{c}\left(N_{c}=Q_{u} / A_{t} S_{u}\right)$ calculated using 3D FEA models are shown in Table 1. The FEA results are compared with empirical test results (Skempton 1951), upper-bound calculation results (Shield and Drucker 1953; Michalowski 2001; Gourvenec et al. 2006), finite difference solutions (Michalowski and Dawson 2002), numerical limit analysis solutions (Salgado et al. 2004) and FEA results (Gourvenec et al. 2006).

\section{Insert Table 1 here.}

For rough foundations, the bearing capacity factor calculated in this paper is 5.87 , which is similar to Gourvenec's result. In addition, the result is lower than both the upper-bound solutions and that between the lower and upper bounds of Salgado et al. (2004). For smooth foundations, the bearing capacity factor calculated in the present paper is 5.53, which is 
similar to Gourvenec's result, lower than the upper-bound solution and greater than the finite difference solution. Thus, the calculation precision of 3D FEA results can be guaranteed.

For the unperforated foundations, the bearing capacity factor $N_{c}$ varies with the dimensionless ratio $\mathrm{kB} / \mathrm{S}_{u o}$, as shown below.

\section{Insert Figure 5 here.}

As shown in Figure 5, the bearing capacity factor of $N_{c}$ shows an increasing attenuation trend as the dimensionless ratio $\mathrm{kB} / \mathrm{S}_{\text {uo }}$ increases. Moreover, this relationship can be predicted using the following linear formulas: $N_{c}=5.87+0.65 \mathrm{kB} / S_{u o}$ for the rough foundation and $N_{c}=5.53+0.43 \mathrm{kB} / S_{u o}$ for the smooth foundation. It is important to note that these formulas are useful in the later study.

\section{Bearing Capacity Analysis}

\subsection{D shallow foundation}

The perforation effect of $2 \mathrm{D}$ shallow foundation is quantified by the change in the perforation correction factor $P_{c}=Q_{u, p} / Q_{u}=Q_{u, p} / N_{c} A_{t} S_{u}$, where $Q_{u, p}$ is the ultimate bearing capacity of perforated foundation, $N_{c}$ is the bearing capacity factor, $S_{u}$ is the undrained shear strength of the bottom level of the foundation, and $A_{t}$ is the total area, ignoring the perforation; i.e., $A_{t}=B$.

The perforation correction factor $P_{c}$ varies with the dimensionless ratio $k B / S_{u o}$, as shown in Figure 6.

\section{Insert Figure 6 here.}

\section{Insert Figure 7 here.}

As shown in Figure 6, the perforation correction factor $P_{c}$ decreases with increasing perforation ratio $R$, and the degree of reduction increases with the increase of the dimensionless ratio $k B / S_{u o}$. The perforation correction factor $P_{c}$ increases with the increase of 
perforation number, and when the perforation number reaches eight, the perforation correction factor $P_{c}$ tends to be stable. This is because the normalized spacing $S / B^{*}$ decreases and tends to stabilize when the perforation number increases to eight (Figure 7). There also exist a critical perforation ratio $R$, when the perforation ratio is lower than the critical perforation ratio, the perforated foundation do not loss the bearing capacity, which meaning the genuine arching effect over the spacing do have a nonnegligible influence on the perforated shallow foundation. This phenomenon is more obvious to the rough foundation on the homogeneous clay. The critical perforation ratio $R$ decreases with the increase of the dimensionless ratio $k B / S_{u o}$.

\subsection{D shallow foundation}

\section{Foundation with a single perforation}

Concentrating on the foundations with single perforation, the perforation effect is also quantified by the change in the perforation correction factor $P_{c}=Q_{u, p} / Q_{u}=Q_{u, p} / N_{c} A_{t} S_{u}$, where $A_{t}$ is the total area, ignoring the perforation; i.e., $A_{t}=B^{2}$, the other symbols are the same as front. The perforation correction factor $P_{c}$ varies with the dimensionless ratio $k B / S_{u o}$, as shown in Figure 8.

\section{Insert Figure 8 here.}

As shown in Figure 8, the perforation correction factor decreases with increasing perforation ratio $R$ and dimensionless ratio $k B / S_{u o}$. The first few results $(0 \leq R \leq 0.1)$ are not strictly linearly distributed but rather have exponential-like distributions. Thus, the influence of the genuine arching effect over the spacing exists but is not obvious. This condition exists because when the perforation ratio is small $(0 \leq R \leq 0.1)$, the influence of the genuine arching effect over the spacing compared with the total bearing capacity is very small and can therefore be ignored, and when the perforation ratio is large $(R \geq 0.1), p_{c}$ can be idealized as 
having a linear distribution. Interestingly, the perforation shape has little influence on the bearing capacity factor relative to the influence of the perforation $R$ and dimensionless $\mathrm{kB} / \mathrm{S}_{u o}$ ratio. The rough foundations still perform better than smooth foundations, in agreement with the $2 \mathrm{D}$ results.

To explore the relationship between $p_{c}$ and $k B / S_{u o}$, the above results are sorted, as shown in Figure 9.

\section{Insert Figure 9 here.}

Figure 9 shows that the perforation correction factor $P_{c}$ decreases with increasing dimensionless ratio $\mathrm{kB} / \mathrm{S}_{\text {uo }}$ and can be described using a linear equation,

$$
p_{c}=\frac{Q_{u, p}}{N_{c} A_{t} S_{u}}=\frac{1}{N_{c}}\left((\alpha-\beta R) \frac{k B}{S_{u o}}+\xi(1-R)\right)
$$

Where $N_{c}=5.87+0.65 \mathrm{kB} / \mathrm{S}_{\text {uо }}$ for rough foundations and $N_{c}=5.53+0.43 \mathrm{kB} / \mathrm{S}_{\text {uo }}$ for smooth foundations, $k$ refers to the linear undrained strength which increases with the depth, $S_{u o}$ refers to the undrained strength at surface level, $B$ refers to the foundation size, and $R$ refers to the perforation ratio of the foundation. The remaining symbols are consistent with those from before. In this formula, $\alpha=0.54, \beta=0.75$, and $\xi=5.95$ are suggested for rough foundations, and $\alpha=0.35, \beta=0.51$, and $\xi=5.5$ are suggested for smooth foundations. It is important to note that the formula (2) is applicable to square foundation with single perforation on soft clay.

This formula is suitable both for circular and square perforations, but note that it is applicable only to shallow embedded square foundation with single perforation and a linearly varying soil strength profile, and the perforation ratio $R$ should be less than 0.7 .

\section{Foundation with multiple perforations}

For foundations with multiple perforations, the perforation correction factor $P_{c}$ is related not only to the perforation ratio $R$ but also to the perforation type and number, as the normalized spacing $S / B^{*}$ may change when the perforation number is changed (Table 1). To 
explore the influence of perforation type and number, a series of models are developed, and the results are plotted together and shown in Figure 10.

\section{Insert Figure 10 here.}

Note that in Figure 10, the square perforation results are shown in black, and the circular perforation results are shown in gray. As shown in Figure 10, the perforation correction factor $P_{c}$ decreases with increasing normalized spacing $S / B^{*}$ for both the square and circular perforations. This is because $S / B^{*}$ decreases as the number of perforations increases when the perforation ratio $R$ is constant, contributing to the excitation of the genuine arching effect over the spacing. In addition, the perforation correction factor $P_{c}$ decreases with increasing dimensionless ratio $\mathrm{kB} / \mathrm{S}_{u o}$, indicating that the impact of the effective augmentation of $\mathrm{kB} / \mathrm{S}_{u o}$ cannot be ignored, regardless of the perforation ratio and perforation number. Finally, it should be noted that the perforation type has little influence on the bearing capacity of the foundation, which is consistent with the analysis of the front single perforation foundation.

To facilitate the use of the above results, the envelopes can be expressed as

$$
p_{c}=\frac{Q_{u, p}}{N_{c} A_{t} S_{u}}=\frac{1}{N_{c}}\left(\alpha \frac{k B}{S_{u o}}+\beta\right)\left(1+\left(\frac{S}{B^{*}}\right)^{2.5}\right)^{-\left(0.2+0.01 \frac{k B}{S_{u o}}\right)}
$$

Where $S / B^{*}$ refers to the normalized spacing, and $\alpha$ and $\beta$ are dimensionless coefficients ( $\alpha$ ranges from 0.41 to 0.43 , and $\beta$ ranges from 5.67 to 6.22 ). $\alpha=0.43$ and $\beta=6.22$ are suggested for rough foundations, and $\alpha=0.41$ and $\beta=5.67$ are suggested for smooth foundations. It is important to note that the formula (3) is applicable to square foundation with multiple perforations on soft clay.

This formula is suitable for both circular and square perforations, but note that it is applicable only to shallow embedded square foundation with multiple perforations and a linearly varying soil strength profile, and the perforation ratio $R$ should be less than 0.9 . 


\section{Conclusion}

This paper presented finite element analyses results for the vertical bearing capacities of 2D and 3D perforated foundations on clay exhibiting a linear increase in undrained strength with depth. The parameters include perforation rate $R$, perforation number, perforation shape and dimensionless ratio $\mathrm{kB} / \mathrm{S}_{u o}$. The conclusions are listed below.

1. For the $2 \mathrm{D}$ foundation, the perforation has a nonnegligible influence on the bearing capacity, and the perforation effect can be quantified by the change in the perforation correction factor $P_{c}$. The perforation correction factor $P_{c}$ decreases with increasing perforation ratio $R$, and the degree of reduction increases with the increase of the dimensionless ratio $k B / S_{u o}$. There exist a critical perforation ratio $R$, when the perforation ratio is lower than the critical perforation ratio, the perforated foundation do not loss the bearing capacity.

2. For the $3 \mathrm{D}$ foundation, the perforation correction factor $P_{c}$ decreases with increasing perforation ratio $R$, normalized spacing $S / B^{*}$ and dimensionless ratio $k B / S_{u o}$. The perforation shape has little influence on the bearing capacity when compared with the influences of $S / B^{*}$ and $k B / S_{u o}$. When the perforation ratio is constant, it is recommended to increase the perforation number to improve the bearing capacity of the foundation.

3. The influence of perforation on the bearing capacity consists of two parts: a genuine arching effect over the spacing and an effective augmentation of $k B / S_{u o}$. The perforation correction factor $P_{c}$ will decrease as the values of $k B / S_{u o}$ increase.

4. Based on the results of the analysis, the relationship between the perforation correction factor $P_{c}$ and normalized spacing $S / B^{*}$ and the dimensionless ratio $k B / S_{u o}$ can be predicted. This prediction is helpful for practical design applications of perforated foundation on soft offshore soils. 


\section{Acknowledgments}

This study was supported by the National Key Basic Research Program of China (2014CB046802).

\section{References}

Bransby, M. F., Brown, M. J., Knappett, J. A., Hudacsek, P., Morgan, N., Cathie, D., and Egborge, R. 2011. Vertical capacity of grillage foundations in sand. Canadian Geotechnical Journal, 48(8), 1246-1265.

Feng, X., Randolph, M. F., Gourvenec, S., and Wallerand, R. 2014. Design approach for rectangular mudmats under fully three-dimensional loading. Géotechnique, 64(1), 51.

Gourvenec, S., Randolph, M., and Kingsnorth, O. 2006. Undrained bearing capacity of square and rectangular footings. International Journal of Geomechanics, 6(3), 147-157.

Gourvenec, S. 2007. Shape effects on the capacity of rectangular footings under general loading. Géotechnique, 57(8), 637-646.

Gourvenec, S. 2008. Effect of embedment on the undrained capacity of shallow foundations under general loading. Géotechnique, 58(3), 177-186.

Gourvenec, S., and Steinepreis, M. 2007. Undrained limit states of shallow foundations acting in consort. International Journal of Geomechanics, 7(3), 194-205.

Kong D, Martin C M, and Byrne, B W. 2017 Modelling large plastic deformations of cohesive soils using sequential limit analysis. International Journal for Numerical \& Analytical Methods in Geomechanics, 41(18), 1781-1806.

Kusakabe, O., Susuki, H., and Nakase, A. 1986. An upper bound calculation on bearing capacity of a circular footing on a nonhomogeneous clay. Soils Foundation, 26(3), 143148.

Li, X., Gaudin, C., Tian, Y., and Cassidy, M. J. 2013. Effect of perforations on uplift capacity of skirted foundations on clay. Canadian Geotechnical Journal, 51(3), 322-331.

Liu, R., and Liu, M. M. 2016. Bearing capacity of composite-strip mudmat foundations for subsea production system on undrained clays. Journal of Hydraulic Engineering, (S1), 74-78.

Liu, R., Liu, M.M., and Ma, W. G. 2016. Design approach of new type of slope-skirted mudmat foundation for subsea production system. Rock and Soil Mechanics, 37(11), 3065-3071.

Martin, C. M., and Hazell, E. C. J. 2005. Bearing capacity of parallel strip footings on non-homogeneous clay. In Proceedings of the International Symposium on Frontiers in Offshore Geotechnics, Perth. 427-433.

Martin, C.M. 2005. Exact bearing capacity calculations using the method of characteristics. Issues lecture, Proc.11th Int. Conf. of IACMAG, Turin, 441-450.

Michalowski, R. L. 2001. Upper bound load estimates on square and rectangular footings. 
Géotechnique 51(9), 787-798.

Micahlowski, R. L., and Dawson, E. M. 2002. Three-dimensional analysis of limit loads on Mohr-Coulomb soil. Foundations of Civil and Environmental Engineering, Vol. 1, Poznan University of Technology Press, Poland, 37-147.

Salgado, R., Lyamin, A. V., Sloan, S. W., and Yu, H. S. 2004. Two and three-dimensional bearing capacity of foundations in clay. Géotechnique, 54(5), 297-306.

Shield, R.T., and Drucker, D.C. 1953. The application of limit analysis to punch indentation problems. Division of Applied Mathematics, 20, 453-460.

Shen, Z., Feng, X., and Gourvenec, S. 2016. Effect of interface condition on the undrained capacity of subsea mudmats under six-degree-of-freedom loading. Géotechnique, 1-12.

Skempton, A.W. 1951. The bearing capacity of clays. Buliding Research Congress, Vol.1, London. 180-189.

Taiebat, H. A., and Carter, J. P. 2000. Numerical studies of the bearing capacity of shallow foundations on cohesive soil subjected to combined loading. Géotechnique, 50(4), 409-418.

Taiebat, H. A., and Carter, J. P. 2002. Bearing capacity of strip and circular foundations on undrained clay subjected to eccentric loads. Geotechnique, 52(1), 61-64.

Taiebat, H. A., and Carter, J. P. 2010. A failure surface for circular footings on cohesive soils. Géotechnique, 60(4), 265-273.

Tapper, L., Byrne, B. W., and Martin, C. M. 2014. Combined load capacity of grillage foundations on loose sand. In C. Gaudin, \& D. White (Eds.), ICPMG2014-Physical Modelling in Geotechnics: Proceedings of the 8th International Conference on Physical Modelling in Geotechnics CRC Press, Boca Raton, FL, USA. Vol. 1. 629-636.

Tapper, L., Martin, C. M., Byrne, B. W., and Lehane, B. M. 2015. Undrained vertical bearing capacity of perforated shallow foundations. Frontiers in Offshore Geotechnics, Fig, 7, 816.

White, D. J., Maconochie, A. J., Cheuk, C. Y., Joray, D., Bolton, M. D., and Springman, S. M. 2005. An investigation into the vertical bearing capacity of perforated mudmats. In Proceedings of the International Symposium on Frontiers in Offshore Geotechnics I, Perth, Australia. 459-465.

Yun, G. J., Maconochie, A., Oliphant, J., and Bransby, F. 2009. Undrained capacity of surface footings subjected to combined VHT loading. In The Nineteenth International Offshore and Polar Engineering Conference. International Society of Offshore and Polar Engineers. 


\section{Figure Captions}

Figure 1 Sketches of 2D footings and symbols

Figure 2 Sketches of 3D shallow foundations and symbols

Figure 3 FEA model mesh strategy, (a) 2D model; (b) 3D model

Figure 4 Bearing capacity factor of unperforated footing

Figure 5 Bearing capacity factor of unperforated foundation

Figure 6 Perforation correction factor for 2D foundation, (a) $k B / S_{u o}=0$ with rough foundation; (b) $k B / S_{u o}=0$ with rough foundation; (c) $k B / S_{u o}=1$ with rough foundation; (d) $k B / S_{u o}=1$ with rough foundation; (e) $k B / S_{u o}=2$ with rough foundation; (f) $k B / S_{u o}=2$ with rough foundation; (g) $k B / S_{u o}=5$ with rough foundation; (h) $k B / S_{u o}=5$ with rough foundation

Figure 7 Normalized spacing $S / B^{*}$ varies with the perforation number

Figure 8 Perforation correction factor for foundations with single perforation, (a) Rough foundation; (b) Smooth foundation

Figure 9 Perforation correction factor for foundation with single perforation, a) Rough foundation; (b) Smooth foundation

Figure 10 Perforation correction factor for foundation with multiple perforations, a) Rough foundation; (b) Smooth foundation 


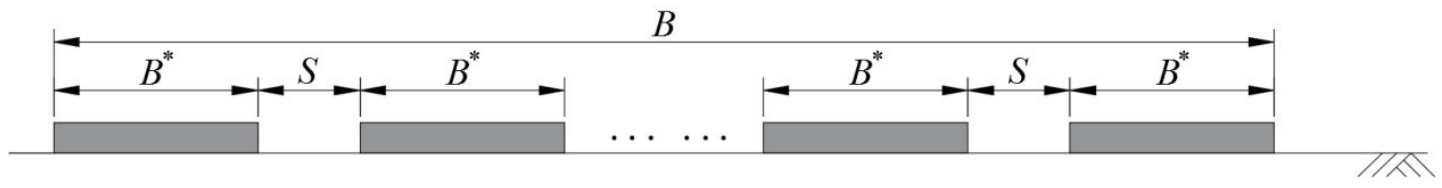

Figure 1 Sketches of 2D footings and symbols
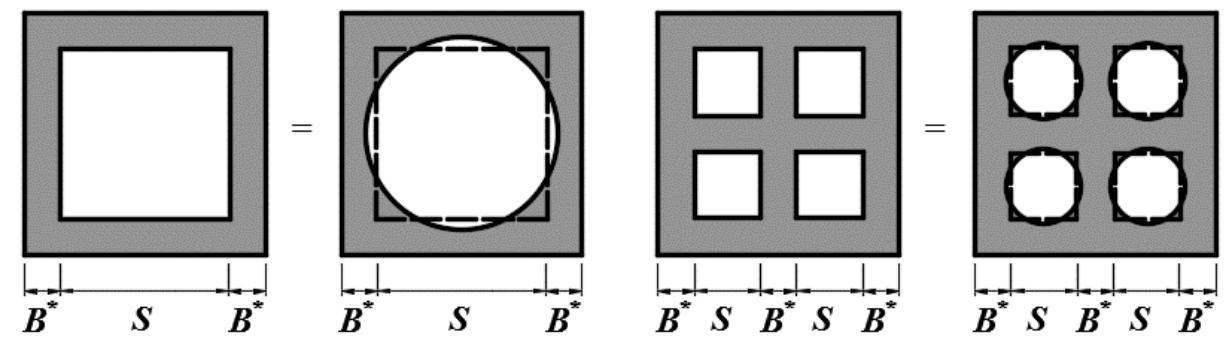

Figure 2 Sketches of 3D shallow foundations and symbols

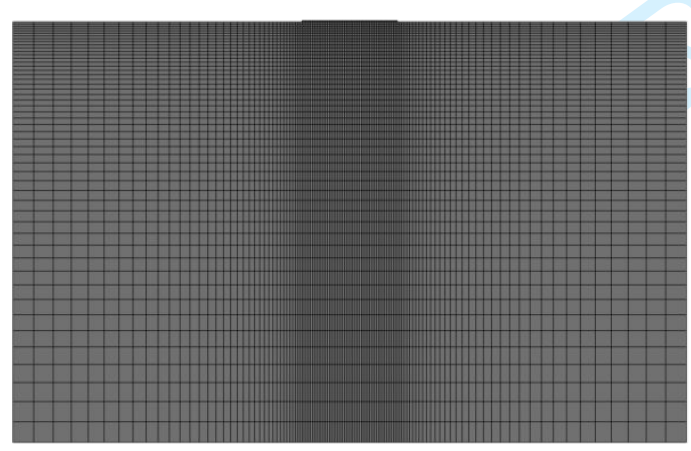

(a) 2D model

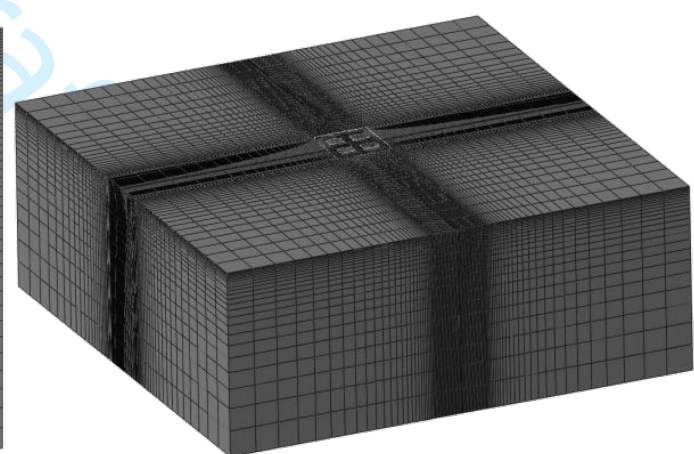

(b) 3D model

Figure 3 FEA model mesh strategy 


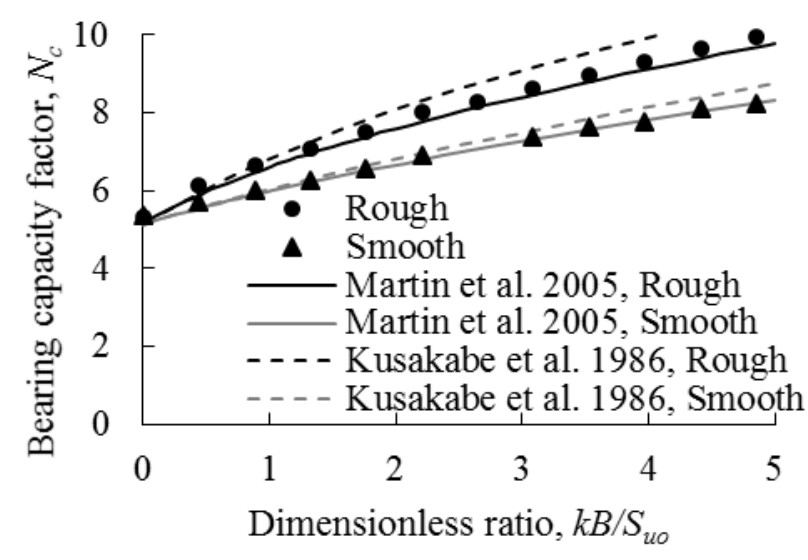

Figure 4 Bearing capacity factor of unperforated footing

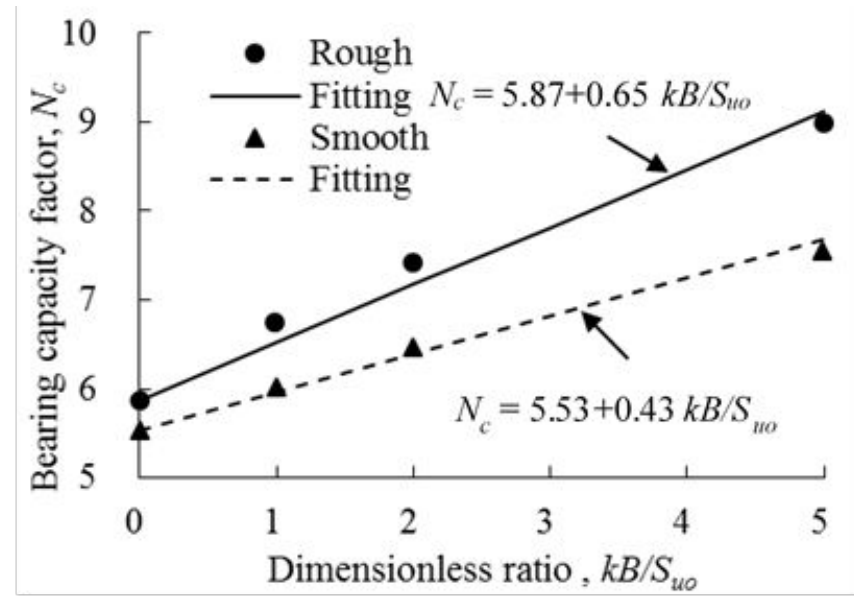

Figure 5 Bearing capacity factor of unperforated foundation 


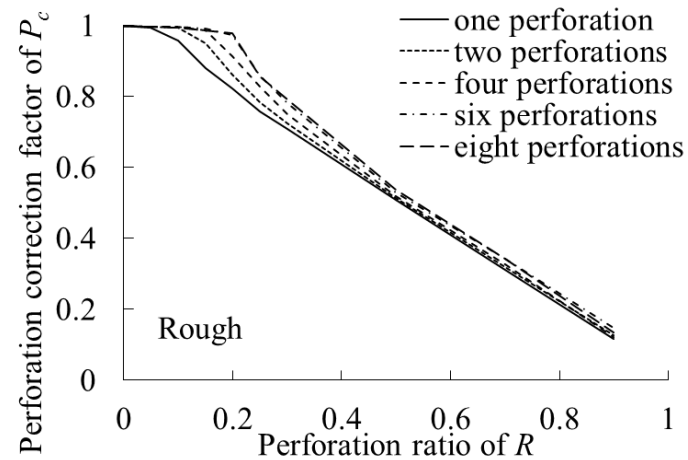

(a) $k B / S_{u o}=0$ with rough foundation

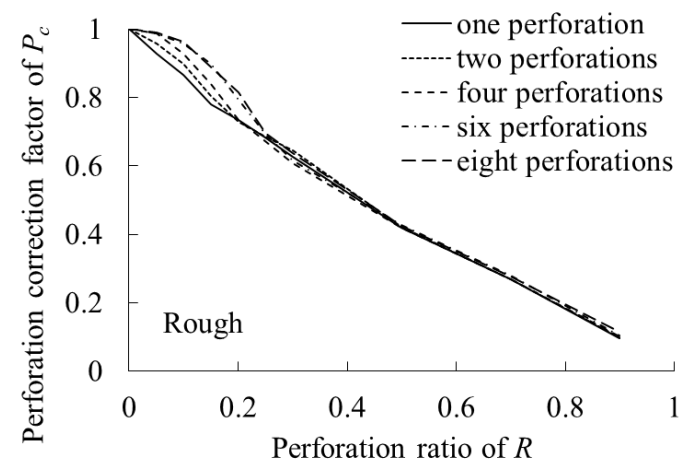

(c) $k B / S_{u o}=1$ with rough foundation

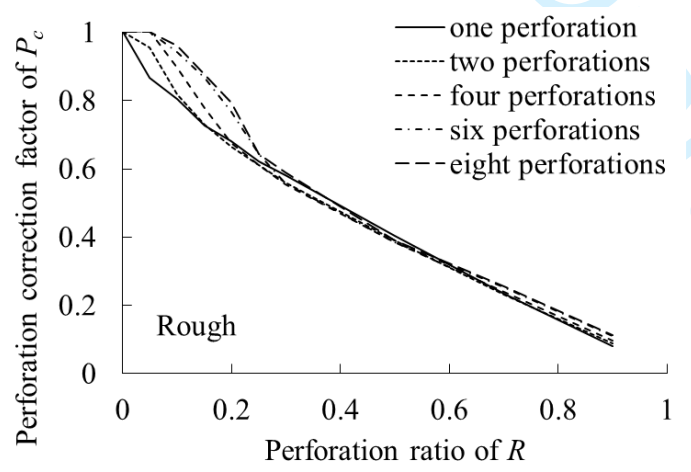

(e) $k B / S_{u o}=2$ with rough foundation

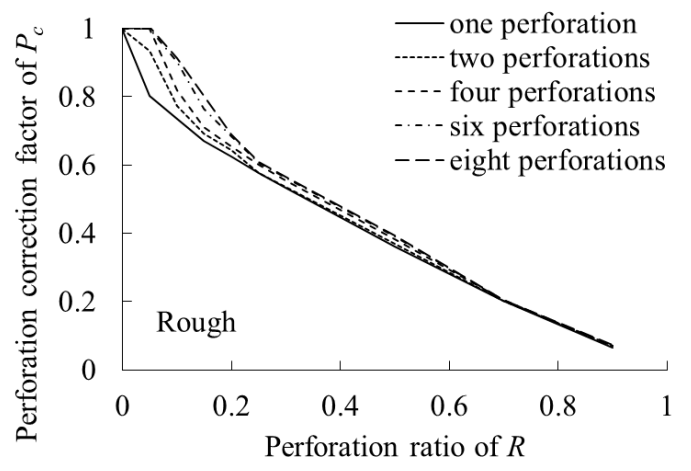

(g) $k B / S_{u o}=5$ with rough foundation

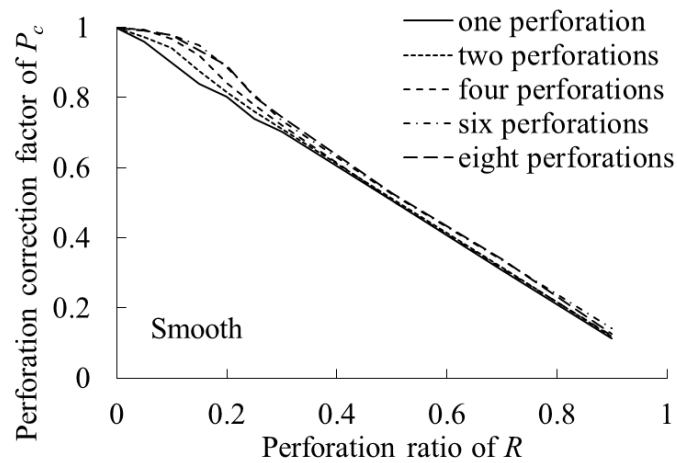

(b) $k B / S_{u o}=0$ with rough foundation

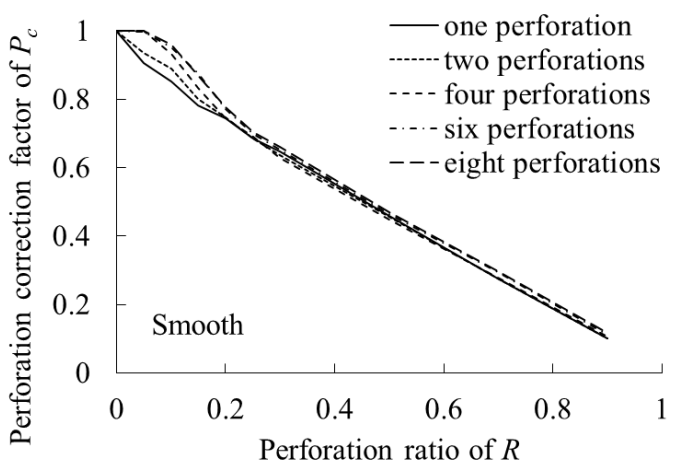

(d) $k B / S_{u o}=1$ with rough foundation

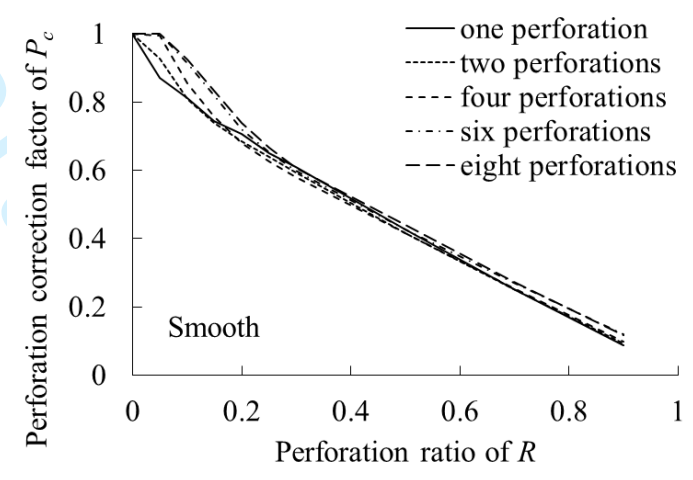

(f) $k B / S_{u o}=2$ with rough foundation

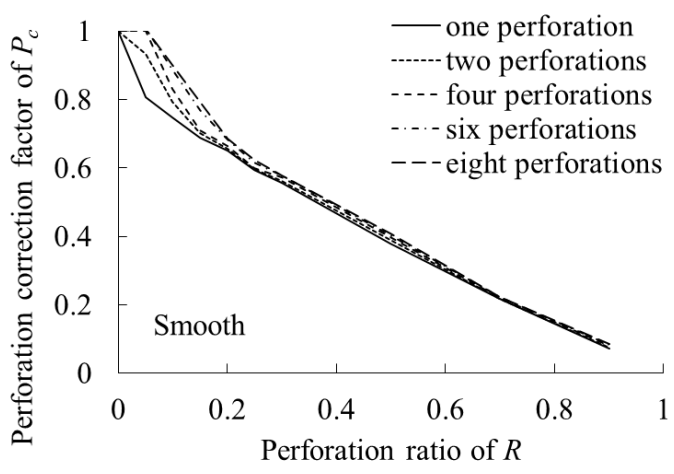

(h) $k B / S_{u o}=5$ with rough foundation

Figure 6 Perforation correction factor for 2D foundation 


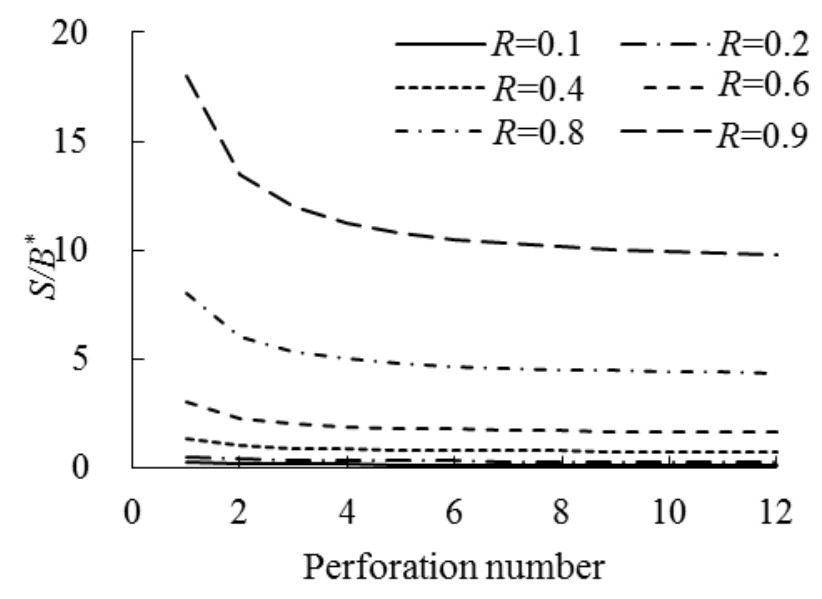

Figure 7 Normalized spacing $S / B^{*}$ varies with the perforation number

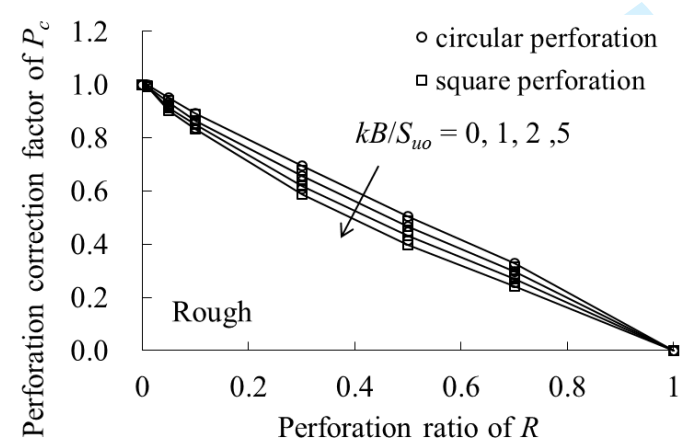

(a) Rough foundation

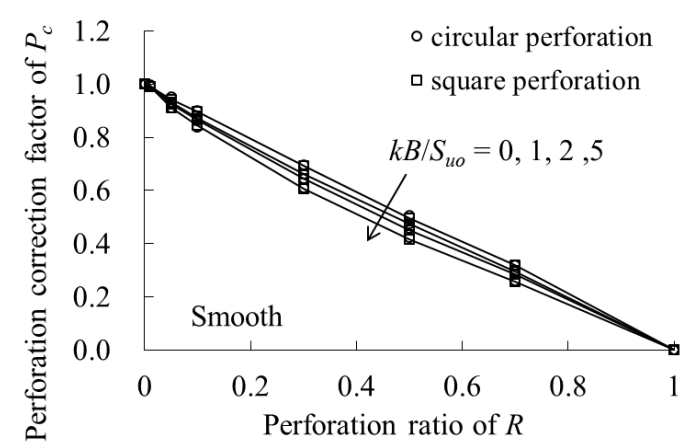

(b) Smooth foundation

Figure 8 Perforation correction factor for foundations with single perforation

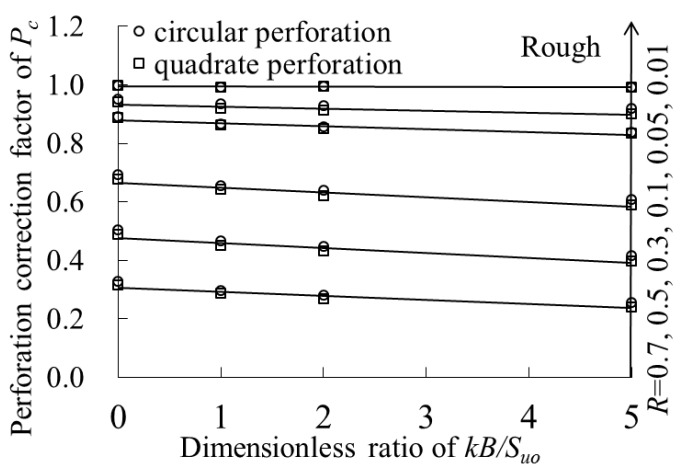

(a) Rough foundation

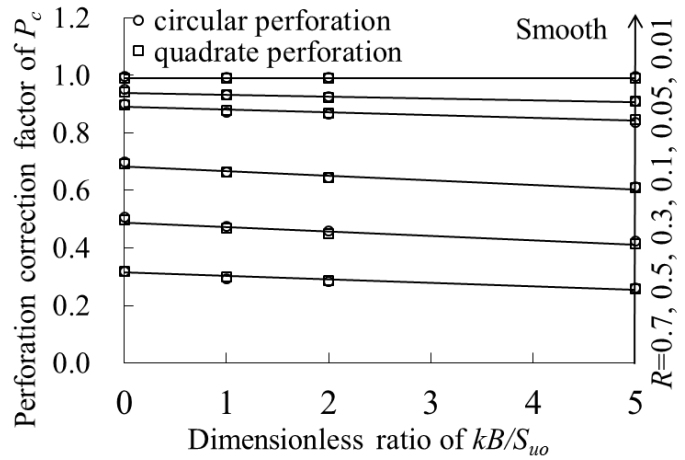

(b) Smooth foundation

Figure 9 Perforation correction factor for foundation with single perforation 


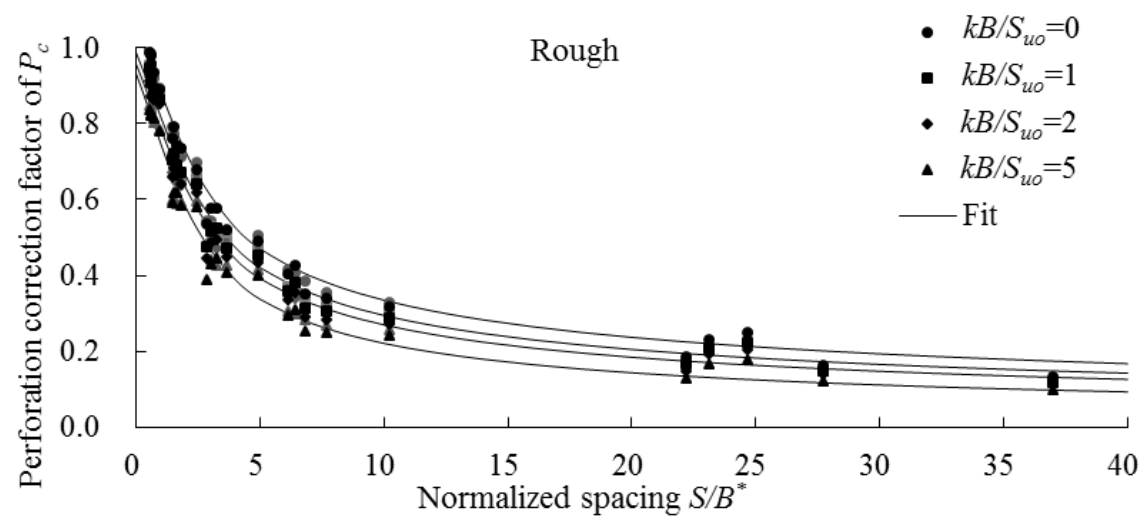

(a) Rough foundation

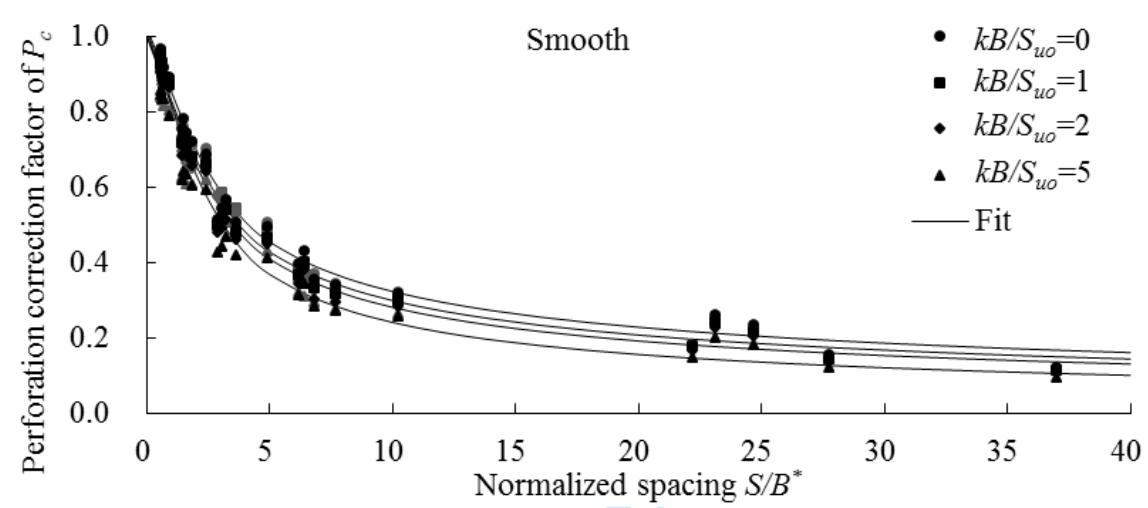

(b) Smooth foundation

Figure 10 Perforation correction factor for foundation with multiple perforations 
Table 1 Bearing capacity factor of unperforated shallow foundations

\begin{tabular}{|c|c|c|c|}
\hline Reference & Analysis type & Contact & $N_{c}$ \\
\hline \multirow{2}{*}{ This study } & \multirow{2}{*}{ FEA } & Rough & 5.87 \\
\cline { 3 - 4 } & & Smooth & 5.53 \\
\hline \multirow{2}{*}{ Gourvenec et al. 2006 } & \multirow{2}{*}{ FEA } & Rough & 5.91 \\
\cline { 3 - 4 } & & Smooth & 5.56 \\
\hline Gourvenec et al. 2006 & Upper bound & Rough & 6.41 \\
\hline Salgado et al. 2004 & Numerical limit & \multirow{2}{*}{ Rough } & 6.22 \\
\cline { 3 - 4 } & analysis & UB \\
\hline Michalowski and Dawson, & Finite difference & Smooth & 5.52 \\
\hline 2002 & Upper bound & Rough & 6.43 \\
\hline Michalowski, 2001 & Upper bound & Smooth & 5.71 \\
\hline Shield and Drucker, 1953 & Empirical & - & 6.17 \\
\hline Skempton, 1951 & \multicolumn{2}{|c}{} \\
\hline
\end{tabular}

